\title{
Polyglutamine Proteins at the Pathogenic Threshold Display Neuron-Specific Aggregation in a Pan-Neuronal Caenorhabditis elegans Model
}

\author{
Heather R. Brignull, Finola E. Moore, Stephanie J. Tang, and Richard I. Morimoto \\ Department of Biochemistry, Molecular Biology, and Cell Biology, Northwestern University Institute for Neuroscience, Rice Institute for Biomedical \\ Research, Northwestern University Evanston, Illinois 60208
}

\begin{abstract}
The basis of neuron-specific pathogenesis, resulting from the expression of misfolded proteins, is poorly understood and of central importance to an understanding of the cell-type specificity of neurodegenerative disease. In this study, we developed a new model for neuron-specific poly $Q$ pathogenesis in Caenorhabditis elegans by pan-neuronal expression that exhibits poly $Q$ length-dependent aggregation, neurotoxicity, and a pathogenic threshold at a length of 35- 40 glutamines. Analysis of specific neurons in C. elegans revealed that only at the threshold length, but not at shorter or longer lengths, polyQ proteins can exist in a soluble state in certain lateral neurons or in an aggregated state in motor neurons of the same animal. These results provide direct experimental evidence that the expression of a single species of a toxic misfolded protein can exhibit a range of neuronal consequences.
\end{abstract}

Key words: polyglutamine; aggregates; neurotoxicity; C. elegans; FRET; FRAP

\section{Introduction}

At least nine human neurodegenerative diseases are caused by the expansion of glutamine $(\mathrm{Q}$, encoded by $\mathrm{CAG})$ repeats within otherwise unrelated genes. In CAG repeat diseases, including Huntington's disease (HD), polyQ expansions are associated with the appearance of misfolded protein species, aggregates, loss of cell function, and cell death (Zoghbi and Orr, 2000; Margolis and Ross, 2001). The expansion of polyQ is thought to cause a fundamental change in protein structure that leads to misfolding, oligomerization, and aggregation (Perutz, 1999; Ross et al., 2003; Poirier et al., 2005).

In vivo, pathogenesis is polyQ length dependent and has been shown to result primarily from a toxic gain of function that has been widely observed in model systems ranging from yeast to mice (Gusella and MacDonald, 2000; Zoghbi and Orr, 2000; Orr, 2001; Sherman and Muchowski, 2003). The pathogenic threshold for polyQ length in most CAG-repeat neurodegenerative diseases is 31-38 repeats. SCA6 (spinocerebellar ataxia type 6) is a notable exception, with a pathogenic threshold of just 18-21 glutamine repeats, which suggests that protein context is a major

\footnotetext{
Received 0ct. 13, 2005; revised June 5, 2006; accepted June 10, 2006.

These studies were supported by grants from the National Institutes of Health (National Institute of General Medical Sciences, National Institute on Aging) and the Huntington Disease Society of America Coalition for the Cure and by National Institute of General Medical Sciences (ellular and Molecular Biology of Disease Training Grant T32 GM08061 (H.R.B.). We thank David Pilgrim (University of Alberta) for generously sharing reagents and Thomas $0^{\prime}$ Halloran (Northwestern University) for the use of microscopes. We also acknowledge Theresa Stiernagle and the Caenorhabditis Genetics Center for providing C. elegans strains. We are grateful to members of the Morimoto laboratory for sharing reagents and for comments on this manuscript.

Correspondence should be addressed to Dr. Richard I. Morimoto, Northwestern University, Department of Biochemistry, 2145 Sheridan Road, Tech MG90, Evanston, IL 60208. E-mail: r-morimoto@northwestern.edu. DOI:10.1523/JNEUROSCI.0990-06.2006

Copyright $\odot 2006$ Society for Neuroscience $\quad$ 0270-6474/06/267597-10\$15.00/0
}

modifier of the pathogenic threshold (Zoghbi and Orr, 2000). In addition to a shared pathogenic motif, gene products associated with CAG repeat diseases are ubiquitously expressed but affect only neurons. Even within neuronal tissues, the polyQ diseases show subset-specific aggregation, toxicity, and death (Ross, 1995; Zoghbi and Orr, 2000).

Caenorhabditis elegans offers unique advantages for modeling neurodegeneration. Transparency of all 959 cells permits ease in detection of fluorescent proteins in live animals. Moreover, the conservation of basic molecular mechanisms, such as those associated with protein-folding quality control and neuronal signaling, enables comparison with vertebrate models (Bargmann and Kaplan, 1998; Brownlee and Fairweather, 1999; Tonkiss and Calderwood, 2005). The morphology and interconnections of all 302 neurons have been mapped by serial section and electron microscopy, and despite having few neurons, C. elegans displays a wide array of complex behaviors. A clear link exists between behavior and the function of neuronal subsets, individual neurons, and genes (Bargmann and Kaplan, 1998; Rankin, 2002). These characteristics make C. elegans an excellent model for examining the effects of toxic proteins on individual neurons in an intact nervous system.

Previous studies using C. elegans to investigate polyQ pathogenesis have limited the expression of polyQ to small subsets of neurons or to the body-wall muscle cells (Faber et al., 1999; Satyal et al., 2000; Parker et al., 2001; Morley et al., 2002). Here, we establish a new C. elegans model in which polyQ proteins are expressed throughout the nervous system. This broad expression pattern, achieved with a pan-neuronal promoter, provides an opportunity to elucidate how different subsets of neurons are simultaneously affected by polyQ expansions in an intact nervous system of a metazoan. Furthermore, it makes it possible to look at 
changes in protein solubility and interactions in a living animal. By the expression of a range of polyQ lengths, we show a polyQ length-dependent threshold of $>$ Q 40 for the formation of visible structures corresponding to immobile polyQ. Aggregates of polyQ tracts $>40$ (Q67 and Q86) form independent of neuronal type, whereas smaller polyQ tracts (Q19, Q35, and Q40) appear soluble by light microscopy. Thus, in our model, the appearance of protein aggregates correlates with the onset of several behavioral phenotypes regulated by specific neurons indicative of polyQ-mediated neurotoxicity. Phenotypes at the critical threshold of Q40 were variable and occurred in the absence of visible aggregates. We used biophysical analyses to reveal that although Q40 does not form discrete foci, solubility and molecular interactions are still altered as compared with subthreshold polyQ expansions; additionally, these changes occur in a neuronspecific manner. Our pan-neuronal model thus recapitulates critical features of polyQ diseases and describes the neuronspecific, biophysical properties of threshold-length polyQ proteins in a live, multicellular organism.

\section{Materials and Methods}

Plasmid constructs. Pan-neuronal polyQ expression was achieved by cloning $3.5 \mathrm{~kb}$ of DNA upstream of the F25B3.3 gene along with the first five codons with a point mutation of the start codon to ATC (gift from David Pilgrim laboratory, University of Alberta, Edmonton, Alberta, Canada). This fragment was cloned into pPD95.79 (gift from Andrew Fire Laboratory, Stanford University, Stanford, CA) between the PstI and Bam HI sites and generated $\mathrm{P}_{\mathrm{F} 25 \mathrm{~B} 3.3}$. Q lengths were established by PCR and inserted into pECFP-N1 (Clontech, Cambridge, UK) between the $K p n \mathrm{I}$ and BamHI sites. $\mathrm{P}_{\mathrm{F} 25 \mathrm{~B} 3.3} \mathrm{Q}(0,19,35,40,67,86)::$ CFP constructs were generated by the addition of a $3^{\prime} B s m I$ site after $\mathrm{Q}(\mathrm{n}) \mathrm{CFP}$ in pECFP-N1 via PCR amplification. The resulting $\mathrm{Q}(\mathrm{n}) \mathrm{CFP}$ fragments and $\mathrm{P}_{\mathrm{F} 25 \mathrm{~B} 3.3}$ were digested with KpnI/Bsm $\mathrm{I}$ and ligated. $\mathrm{P}_{\mathrm{F} 25 \mathrm{~B} 3.3} \mathrm{Q}(\mathrm{n}):: \mathrm{YFP}$ constructs were generated by removing CFP from $\mathrm{P}_{\mathrm{F} 25 \mathrm{~B} 3.3} \mathrm{Q}(\mathrm{n}):: \mathrm{CFP}$ and inserting YFP from pEYFP-N1 (Clontech) between AgeI and NotI. Sequencing confirmed the construction of plasmids and Q length. Promoter selection was critical; earlier attempts with an unc-119 promoter were not successful, possibly because of the early expression (60 cell stage) of the promoter versus the $\mathrm{F} 25 \mathrm{~B} 3.3$ promoter, which becomes active at $\sim 450$ min of embryonic development, a time postmitotic for the neuroblasts (Altun-Gultekin et al., 2001).

C. elegans methods. Nematodes were raised and handled by standard methods (Brenner, 1974). For the generation of transgenic animals, DNA encoding $\mathrm{P}_{\mathrm{F} 25 \mathrm{~B} 3.3} \mathrm{Q}(0,19,35,40,67,86):: \mathrm{CFP}$ or YFP was injected into $\mathrm{N} 2$ at $50 \mathrm{ng} / \mu \mathrm{l}$. At least three independent lines for each transgene were isolated and analyzed. Integrated lines expressing Q40 were generated by gamma irradiation of transgenic animals expressing $\mathrm{P}_{\mathrm{F} 25 \mathrm{~B} 3.3} \mathrm{Q} 40:: \mathrm{YFP}$. Two independently isolated lines, AM101 rmIs110 and AM102 rmIs111, were each backcrossed a minimum of five times with N2. Populations were synchronized by treating young adult animals with alkaline hypochlorite solution $(0.5 \mathrm{M} \mathrm{NaOH}, \sim 2.6 \% \mathrm{NaOCl})$ or by collecting embryos laid by adult animals during a $3 \mathrm{~h}$ period.

Strains. All strains used the F25B3.3 promoter with some Q length fused to either cyan fluorescent protein (CFP) or yellow fluorescent protein (YFP). CFP lines included the following: (Q0) AM84 rmEx155; (Q19) AM282 rmEx95; (Q35) AM303 rmEx116; (Q40) AM305 rmEx118; (Q67) AM308 rmEx121; and (Q86) AM313 rmEx126. YFP lines included the following: (Q0) AM277 rmEx90; AM279 rmEx92; and (Q19) AM285 rmEx98, AM287 rmEx100; and (Q35) AM78 rmEx158, AM80 rmEx157; and (Q40) AM85 rmEx159, AM87 rmEx160; and (Q67) AM81 rmEx164, AM83 rmEx162; and (Q86) AM322 rmEx135, AM324 $\mathrm{rmEx} 137$. Dual-colored lines for imaging and fluorescence resonance energy transfer (FRET) included AM333 $\operatorname{rmEx} 146\left[\mathrm{P}_{\mathrm{F} 25 \mathrm{~B} 3.3} \mathrm{YFP} ; \mathrm{P}_{\mathrm{F} 25 \mathrm{~B} 3.3} \mathrm{CFP}\right]$,

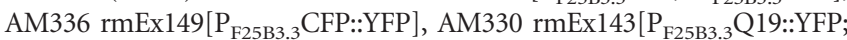
$\left.\mathrm{P}_{\text {F25B3.3 }} \mathrm{Q} 19:: \mathrm{CFP}\right], \mathrm{AM} 327 \mathrm{rmEx} 140\left[\mathrm{P}_{\mathrm{F} 25 \mathrm{~B} 3.3} \mathrm{Q} 86:: \mathrm{YFP} ; \mathrm{P}_{\mathrm{F} 25 \mathrm{~B} 3.3} \mathrm{Q} 86:: \mathrm{CFP}\right]$, and AM66 rmEx165[ $\left.\mathrm{P}_{\mathrm{F} 25 \mathrm{~B} 3.3} \mathrm{YFP} ; \mathrm{P}_{\mathrm{F} 25 \mathrm{~B} 3.3} \mathrm{Q} 86:: \mathrm{CFP}\right]$.

Behavioral assays. All assays were performed at room temperature $\left(\sim 23^{\circ} \mathrm{C}\right)$ on animals synchronized to $4 \mathrm{~d}$ old and grown at $20^{\circ} \mathrm{C}$. Thrashing rate was determined by placing individual animals in a drop of M9, allowing $1 \mathrm{~min}$ for recovery, and then counting body bends for $30 \mathrm{~s}$. A body bend was defined as change in direction of the bend in the midbody of an animal (Chai et al., 2002). For each Q length assayed, $n \geq 50$, with at least two independent transgenic lines per Q length. Pharyngeal pumping rate was determined by counting the number of contractions per minute of the terminal bulb of the pharynx (Sze et al., 2000). For each Q length assayed, $n \geq 90$, with at least two independent transgenic lines for each Q length. Defecation cycle was the time between contractions of the posterior body-wall muscles. For N2, $n=10$, and for each polyQ strain, a minimum of 30 animals were timed for 10 cycles (Dal Santo et al., 1999). The $p$ values from unpaired, two-tailed $t$ tests and percentage coefficient of variation [calculated as $(\mathrm{SD} /$ mean $) \times 100 \%$ ] are shown for all behavioral assays in supplemental Figure 4 (available at www.jneurosci.org as supplemental material).

Imaging. Fluorescence recovery after photobleaching (FRAP) was performed on 4 - or 5 -d-old animals. Imaging was at $0.1 \%$ power of a $514 \mathrm{~nm}$ laser, and bleaching was 10 iterations at $100 \%$ power. Relative fluorescence intensity (RFI) was determined with the following equation: $\mathrm{RFI}=$ $\left(T_{\mathrm{t}} / C_{\mathrm{t}}\right) /\left(T_{0} / C_{0}\right)$, with $T_{0}$ representing the total intensity of the region of interest before photobleaching and $T_{\mathrm{t}}$ the intensity in the same area at any time after. We normalized against an unbleached area in the same cell, where $C_{0}$ is a control area before bleaching and $C_{\mathrm{t}}$ represents any time after bleaching (Phair and Misteli, 2000).

FRET experiments were performed by the combined acceptor and donor photobleaching method on 4-d-old animals (Wouters et al., 1998; Berney and Danuser, 2003). YFP excitation was $5 \%$ power of a $514 \mathrm{~nm}$ laser, and bleaching was 50 iterations at $100 \%$ power. CFP excitation was $5 \%$ power of a $458 \mathrm{~nm}$ laser. The efficiency of interactions $\left(E_{\mathrm{i}}\right)$ was calculated by determining CFP intensity (post-bleach - pre-bleach)/ (post-bleach) (Wouters et al., 1998). Cells with $>30 \%$ YFP intensity remaining after bleaching were excluded from analysis (Berney and Danuser, 2003). All images were obtained on a Zeiss (Oberkochen, Germany) LSM 510 confocal microscope under a $63 \times$ water objective. Animals were immobilized with $1 \mathrm{~mm}$ levamisole and mounted on a pad of $3 \%$ agarose.

\section{Results}

\section{Pan-neuronal expression of polyQ proteins in C. elegans} reveals length-dependent changes in protein distribution

We have generated transgenic animals expressing a range of polyQ expansion proteins, tagged with CFPs or YFPs, in neurons under the control of the promoter for F25B3.3. The gene product of this promoter is the C. elegans ortholog of a $\mathrm{Ca}^{2+}$-regulated Ras nucleotide exchange factor, RasGRP (guanyl nucleotidereleasing protein), which is expressed throughout the vertebrate nervous system and in C. elegans beginning late in the comma stage of embryogenesis (Ebinu et al., 1998; Kawasaki et al., 1998). YFP fluorescence is uniform throughout the nervous system, suggesting that the $\mathrm{F} 25 \mathrm{~B} 3.3$ promoter is an appropriate choice for a pan-neuronal model in which to evaluate the response of different neurons to polyQ proteins.

In young adult (day 4) animals, expression of Q19 fused to CFP (Q19) resulted in a pattern of diffuse neuronal distribution that was first visible during the L1 stage of development and persisted throughout the life of the animal. Q19 is visible in both the cytoplasm and nucleus of neuronal cell bodies and appears diffuse throughout neuronal processes (Fig. $1 A, B$ ) in a pattern similar to that of control animals expressing only CFP or YFP (Q0) (data not shown) (Altun-Gultekin et al., 2001). In Q19 animals, cell bodies of commissural neurons (Fig. $1 B$, thin arrow) and the dorsal nerve cord (DNC) (Fig. $1 B$, thick arrow) can be observed. The DNC is formed almost exclusively of neuronal processes and displays a smooth, diffuse fluorescent intensity in Q19 animals. Similarly, the ventral nerve cord (VNC) displays a 

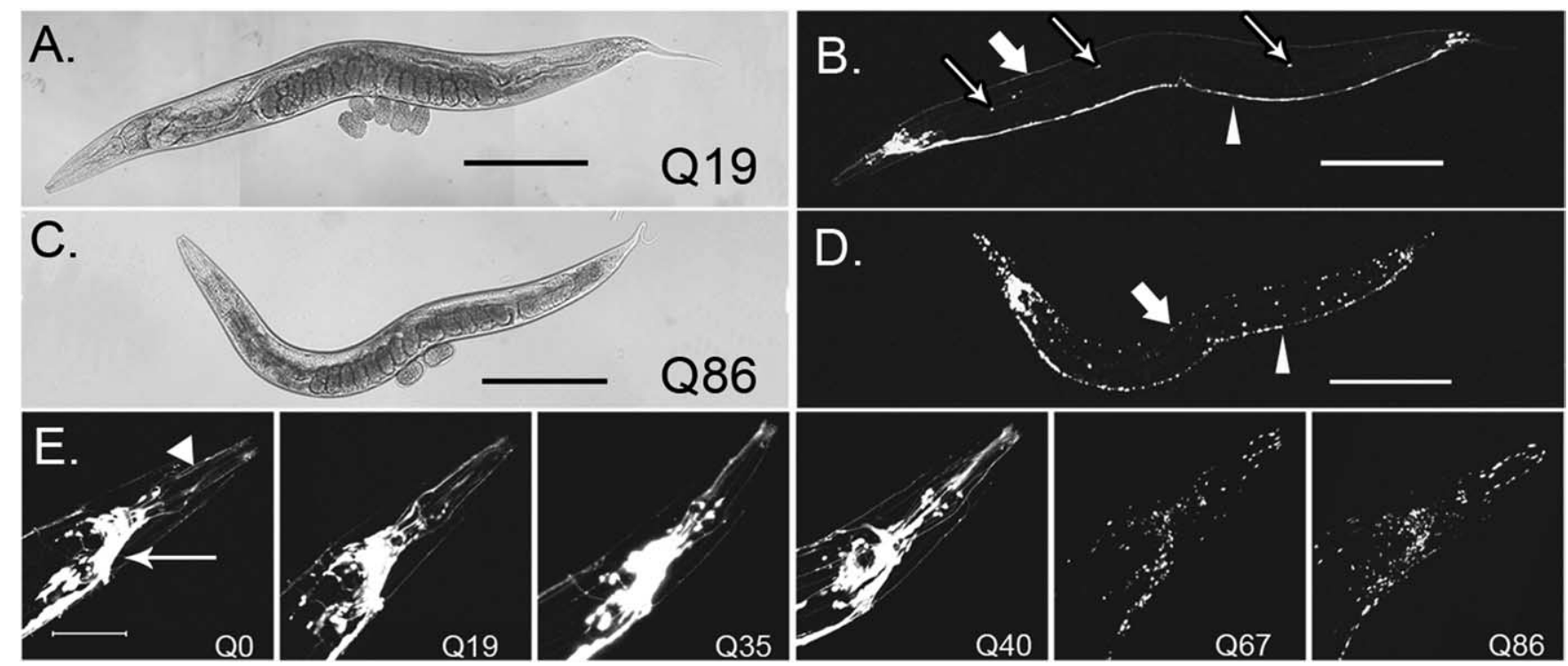

Figure 1. Pan-neuronal $019::$ CFP has a soluble distribution pattern $(\boldsymbol{A}, \boldsymbol{B})$, whereas $086::$ CFP is distributed into discrete foci $(\boldsymbol{C}, \boldsymbol{D})$. Thin arrows indicate commissural neurons. Thick arrow indicates DNC; triangle indicates VNC. Scale bar, $100 \mu \mathrm{m}$. $\boldsymbol{E}$, Flattened z-stacks of C. elegans head. Arrow indicates circumpharyngeal nerve ring; triangle indicates processes of chemosensory neurons. Scale bar, $50 \mu \mathrm{m}$. Expression of a range of polyQ lengths reveals that proteins with tracts that are equal to or less than that of Q40 maintain a soluble distribution pattern, whereas those equal to or more than 067 form foci. All animals depicted are young adults (4 d post-hatch).

smooth, diffuse appearance from the neuronal processes and cell bodies along its length (Fig. $1 B$, triangle).

Animals that express proteins containing Q86 fused to CFP (Q86) are typically smaller and more lethargic than Q0 or Q19 animals. Despite this, Q86 animals develop to adulthood and have progeny within a day of Q19 animals; consequently, the rate of development is similar. The distribution of Q86 protein is strikingly different from the diffuse distribution of Q19 protein. Throughout the nervous system, Q86 protein is localized to discrete foci, which suggests that polyQ length-dependent aggregation occurs in C. elegans neurons (Fig. $1 C, D$ ). Foci formation is particularly evident in the VNC (Fig. $1 D$, triangle) and the DNC (Fig. $1 D$, thick arrow), where foci formation disrupts the continuous fluorescence observed in animals expressing Q19 (Fig. $1 B$ ). Cytoplasmic polyQ foci (supplemental Fig. 2, available at www. jneurosci.org as supplemental material) appear in both cell bodies (supplemental Fig. $1 A-D$, available at www.jneurosci.org as supplemental material) and neuronal processes (supplemental Fig. $1 C-E$, available at www.jneurosci.org as supplemental material) and are observed typically as one aggregate per cell body. Q86 foci are detected in the first larval stage and persist throughout the lifespan of the animals (data not shown). These results show that in the presence of large polyQ expansions, all neurons in C. elegans, independent of subtype, are susceptible to the formation of polyQ foci.

To determine whether intermediate polyQ proteins might display neuron-specific foci formation, it was necessary to establish the pathogenic polyQ threshold in C. elegans neurons. We therefore expressed a range of intermediate lengths of Q35, Q40, and Q67 fused to a fluorescent reporter. Animals expressing proteins equal to or less than that of Q40 showed clearly delineated neuronal cell bodies and processes, suggesting the presence of soluble polyQ protein. The soluble distribution pattern of Q0, Q19, Q35, and Q40 can be clearly observed in the head neurons of C. elegans, where the distinctive neuroanatomy of chemosensory processes (Fig. $1 E$, triangle) and the circumpharyngeal nerve ring can be identified (Fig. 1E, arrow) (Bargmann and Kaplan, 1998).
Q67 formed foci exclusively, similar to the foci observed in neurons of Q86 expressing C. elegans (Fig. 1E). Restated, the distribution pattern of proteins equal to or less than that of Q40 are consistently distinct from that of Q67 or Q86. The polyQ lengthdependent changes in protein distribution shown here, together with a threshold for foci formation of more than Q40, recapitulate two of the major features of most CAG-repeat diseases.

\section{Biophysical properties of polyQ proteins in neurons of live animals}

The soluble distribution pattern equal to or less than that of Q40 protein is visually distinct from Q67 and Q86. To assess whether the visual changes in subcellular distribution correspond to changes in polyQ protein solubility, we used FRAP analysis. The rate of recovery after photobleaching in an individual neuron provides a direct measure of protein solubility (White and Stelzer, 1999; Lippincott-Schwartz and Patterson, 2003) and enabled us to discriminate between changes in distribution caused by protein aggregation, in which interacting proteins are stably associated and immobile, and changes caused by restricted subcellular localization.

FRAP experiments on live animals that express a soluble control, Q0 or Q19, show rapid recovery from photobleaching (Fig. $2 A, B)$, from which we conclude that these proteins are in a soluble state within neurons (Fig. 2D). By comparison, the foci in Q86 neurons do not recover after photobleaching, indicating that Q86 is immobile because of the formation of polyQ aggregates (Fig. 2C,D). This aggregation state was observed in all neurons examined in Q86 animals, from which we conclude that there is no variation among neuronal cell types when very large glutamine expansions are expressed. Western blot analysis also showed that Q86 aggregates were resistant to 5\% SDS treatment (data not shown), which is characteristic of the biochemical properties of polyQ aggregates (DiFiglia et al., 1997; Scherzinger et al., 1999). Likewise, extracts of Q67 animals also contained SDS-resistant aggregates, whereas extracts from Q40- and Q19expressing animals did not contain detectable aggregates by 
Western blot analysis (supplemental Fig. 3, available at www.jneurosci.org as supplemental material). Therefore, for the purpose of our analysis of protein aggregation in C. elegans neurons, we define aggregates principally by the in vivo demonstration of visually distinct foci that are immobile and SDS resistant.

We next examined whether the neuronal polyQ aggregates display intermolecular interactions to extend the resolution of our analysis from behavioral phenotypes down to the behavior of specific proteins in a live animal. It has been proposed that polyQ expansions cause the formation of $\beta$-sheet structures that self-associate and lead to aggregation (Perutz, 1999; Ross et al., 2003). This hypothesis predicts that in addition to being immobile and resistant to SDS, polyQ proteins in aggregate structures may be in close proximity. To address this, we used FRET, a technique developed for in vitro biochemical studies and applied to cell culture to show, in vivo, the proximity of two proteins. The resolution of this technique is in the nanometer range; FRET is maximal at $50 \AA$ and will not occur if proteins are $>100 \AA$ apart. The second requirement for FRET is that proteins are appropriately and stably oriented to enable dipole-dipole interactions between fluorophores; proteins must be approximately parallel for energy transfer between fluorophores (Miyawaki and Tsien, 2000; Miyawaki, 2003). This technique has been widely used to show protein interactions in vitro and in cell culture (Tsien, 1998; Kim et al., 2002). We therefore performed FRET experiments to determine whether polyQ proteins in C. elegans neurons are in the molecular proximity required for energy transfer to occur between CFP and YFP fluorophores.

To establish whether FRET efficiencies $\left(E_{\mathrm{i}}\right)$ could be determined in neurons of a living animal, we generated as a positive control C. elegans expressing a CFP::YFP chimera with a flexible linker separating the two fluorophores (Kim et al., 2002). The $E_{\mathrm{i}}$ in neurons of temporarily immobilized animals was determined by using the acceptor photobleaching technique in which donor (CFP) intensity is compared before and after acceptor (YFP) photobleaching (Berney and Danuser, 2003). These data are typically visualized as ratio images; however, even immobilized C. elegans are not completely still during imaging, and this can cause three-dimensional misalignment of sequential images, thus hindering alignments to obtain ratio images. Therefore, representative images from FRET experiments display individual images before and after YFP bleaching for both acceptor and donor in-
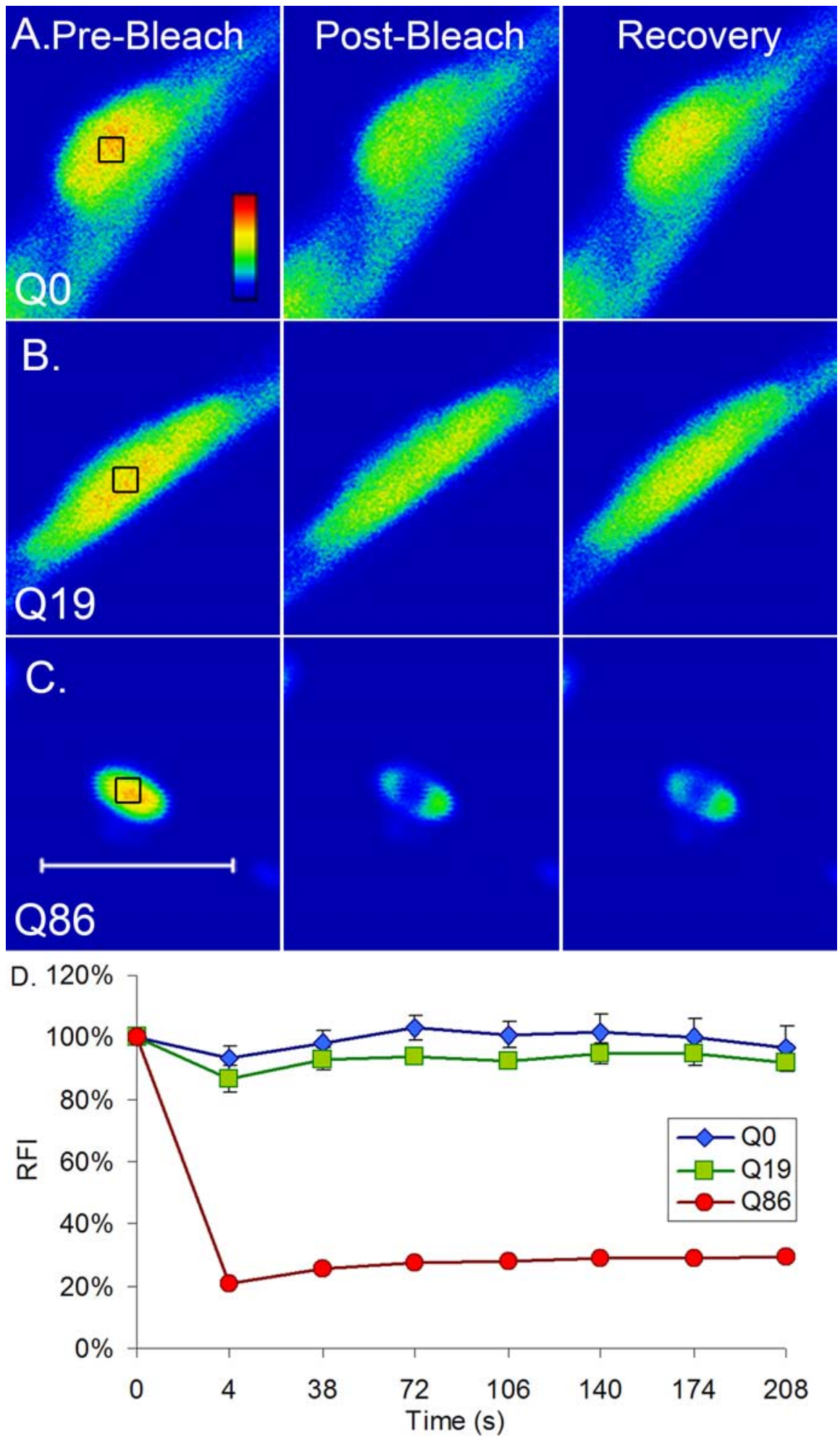

Figure 2. FRAP in C. elegans neurons expressing Q19::YFP, a photobleached area (box), recovers rapidly $(\boldsymbol{B}, \boldsymbol{D})$, similar to Q0 $(\boldsymbol{A}$, $D$ ), indicating soluble proteins, whereas bleached Q86::YFP foci do not recover $(\boldsymbol{C}, \boldsymbol{D})$. Therefore, Q86::YFP foci are insoluble, consistent with aggregation. Quantification $(\boldsymbol{D})$ is five or more experiments with SEM. Signal intensity is measured in the color scale $(\boldsymbol{A})$, where blue is least intense and red is most intense. Scale bar, $5 \mu \mathrm{m}$. RFl, Relative fluorescence intensity.

tensity (Fig. 3). The calculation of $E_{\mathrm{i}}$ included a control area outside of the photobleached region to correct for any movement of the animal.

FRET experiments performed on the neuronal CFP::YFP positive control through bleaching of the YFP acceptor (Fig. $3 A$ ) 

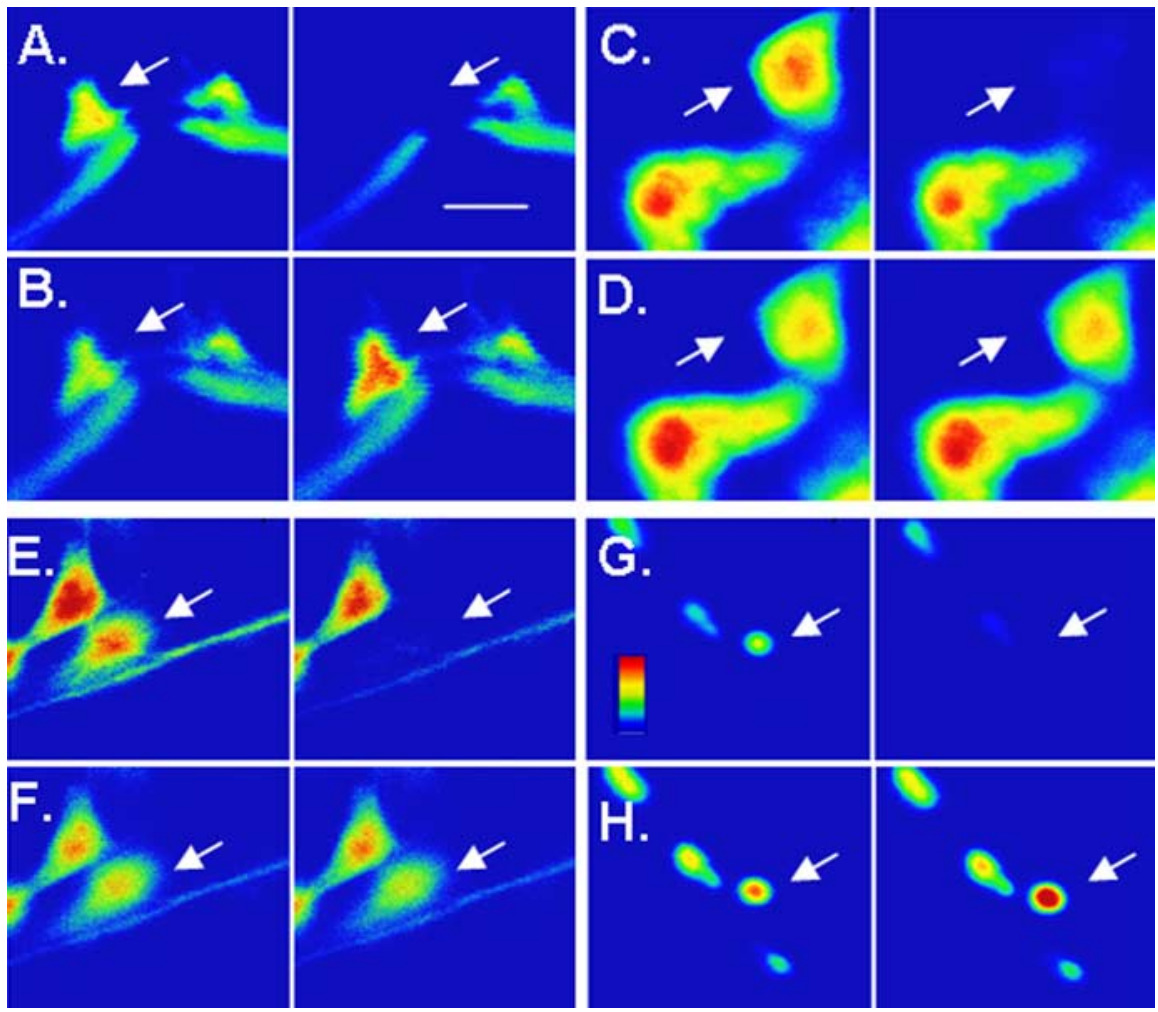

Figure 3. Q86 protein in neuronal aggregates exhibits FRET, indicating close and roughly ordered interactions at the molecular level. $\boldsymbol{A}, \boldsymbol{C}, \boldsymbol{E}, \boldsymbol{G}$, YFP channel, before and after photobleaching. $\boldsymbol{B}, \boldsymbol{D}, \boldsymbol{F}, \boldsymbol{H}$, CFP intensity in the same cell before and after YPP photobleaching. Animals expressing CFP.:.YFP FRET $(\boldsymbol{A}, \boldsymbol{B}), \boldsymbol{E}_{\mathrm{i}}=0.248( \pm 0.089)$. CFP and YFP coexpression $(\boldsymbol{C}, \boldsymbol{D})$ do not produce FRET,$E_{\mathrm{i}}=0.001$ ( \pm 0.025). Neurons coexpressing Q19::CFP and Q19::YFP $(\boldsymbol{E}, \boldsymbol{F})$ do not produce FRET, $E_{\mathrm{i}}=-0.090$ ( \pm-0.057 ), whereas coexpression of $Q 86::$ CFP and Q86::YFP $(\boldsymbol{G}, \boldsymbol{H})$ does produce FRET, $E_{\mathrm{i}}=0.224( \pm 0.076)$. Cells shown are representative of FRET experiments. Intensity is by a color scale $(\mathbf{G})$ : blue is least intense and red is most intense. Arrows indicate the cell being analyzed for FRET. Scale bar, $2 \mu \mathrm{m}$.

resulted in increased donor (CFP) intensity as expected: $E_{\mathrm{i}}=$ 0.248 ( \pm 0.089 ) (Fig. 3B). As a negative control, animals coexpressing CFP and YFP from separate constructs were tested. After YFP photobleaching (Fig. $3 C$ ), there was no increase in CFP intensity (Fig. 3D), revealing as expected the absence of a detectable FRET signal: $E_{\mathrm{i}}=0.001$ ( \pm 0.025 ). With FRET efficiencies from control animals as reference points, $C$. elegans expressing both Q19::CFP and Q19::YFP were then tested. YFP photobleaching (Fig. 3E) had no effect on CFP intensity, $E_{\mathrm{i}}=-0.090( \pm-0.057)$ (Fig. $3 F$ ), which was similar to the results obtained with negative control animals (Fig. 3C,D). In contrast, animals coexpressing Q86::CFP and Q86::YFP showed an increase in CFP intensity (Fig. $3 H$ ) after YFP photobleaching, $E_{\mathrm{i}}=0.224( \pm 0.076)$, which was similar in intensity to the CFP::YFP positive control (Fig. $3 G)$. FRET-positive aggregates were detected in all neurons examined, with no apparent relationship between FRET intensity and neuronal cell type. The visible redistribution of Q67 and Q86 into foci, combined with SDS resistance and FRAP and FRET data from neurons of living animals, shows that in the nervous system of C. elegans, all neurons are susceptible to the formation of insoluble, ordered aggregates from large polyQ expansions.

\section{PolyQ length-dependent aggregation correlates with neuronal dysfunction}

In human disease, and in mouse, Drosophila, and cell culture studies of polyQ pathogenesis, aggregation is often accompanied by cellular dysfunction, although growing evidence supports intermediate oligomeric states as the toxic species (Ross and
Poirier, 2004). To test whether polyQ aggregation in C. elegans neurons is accompanied by neurotoxicity, we examined behavioral phenotypes regulated by the nervous system. The most striking phenotype was a polyQ length-dependent loss of coordinated movement leading to nearly complete paralysis. More than 60 neurons in C. elegans enervate muscle cells, with the dysfunction or loss of these neurons resulting in a lack of coordination or paralysis (White et al., 1976, 1986; Rand and Nonet, 1997). The motility of polyQexpressing animals was quantified by determining the frequency with which animals thrashed when in liquid (Chai et al., 2002). Q0 or Q19 animals with no visible polyQ aggregates showed rapid movement similar to wild-type (N2) animals, although Q19 animals showed a slight decrease in movement. By comparison, animals expressing Q67 and Q86 exhibited an 85 and $89 \%$ decrease, respectively, in thrashing relative to Q0 animals (Fig. 4 and supplemental Fig. $4 A$, available at www.jneurosci.org as supplemental material). These results show that the formation of visible polyQ aggregates correlates with overt neuronal dysfunction in $C$. elegans.

To address whether polyQ-mediated toxicity affects other neuronal phenotypes, we tested pharyngeal pumping rates and defecation cycle length. These behaviors are regulated by smaller subgroups of neurons that act largely independently of the cells that regulate motility. Contraction rates of the pharynx are regulated by 20 neurons that constitute the pharyngeal nervous system and are connected to the rest of the nervous system by only two neurons (Albertson and Thomson, 1976; Avery and Horvitz, 1989; Avery, 1993). Despite the relative isolation of the pharyngeal nervous system, pharyngeal pumping rates also show a polyQ lengthdependent decrease. Pharyngeal pumping rates in animals that express Q19 are similar to wild type and Q0, whereas Q67 and Q86 animals exhibit a decrease of 31 and 38\%, respectively, from Q0 animals (supplemental Fig. 4B, available at www.jneurosci.org as supplemental material).

The defecation cycle length in C. elegans is influenced by two pairs of neurons (McIntire et al., 1993). Cycle length is not affected by pan-neuronal expression of Q0 or Q19, and these animals maintain a highly rhythmic behavior similar to wild type (supplemental Fig. 4C, available at www.jneurosci.org as supplemental material); however, animals that express Q67 or Q86 exhibit a more erratic cycle that is reduced by 12 and $15 \%$, respectively (supplemental Fig. 4C, available at www.jneurosci.org as supplemental material). Despite differences in severity, all three behavioral assays show length-dependent, polyQ-mediated neurotoxicity in C. elegans.

Unexpectedly, pan-neuronal expression of the intermediate polyQ lengths, Q35 and Q40, also affects behavior; however, in contrast to the clear phenotypic differences observed between transgenic animals that express short or long polyQ proteins, individual Q35 and Q40 animals displayed heterogeneity in be- 


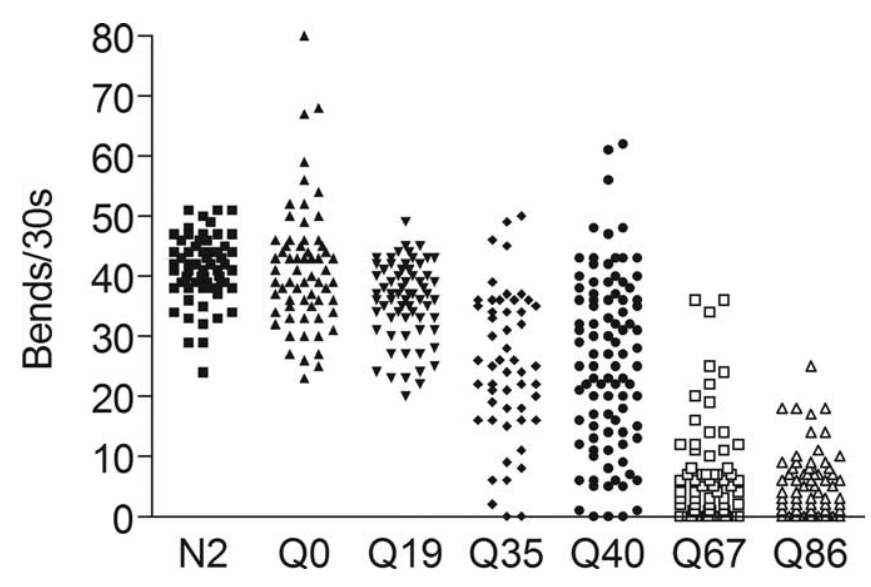

Figure 4. Increases in polyQ length correlate with neuronal dysfunction. Each point represents the average thrashing rate of a single young adult animal (4 d) over a period of $30 \mathrm{~s}$. A bar graph and statistical analysis of these data can be found in supplemental Figure 3 (available at www.jneurosci.org as supplemental material).

havioral phenotypes (Fig. 4). These results did not seem to correlate with the apparent soluble distribution pattern of Q35 and Q40 proteins, which was visually distinct from the extensive foci formation in Q67 and Q86 animals (Fig. 1E). Several hypotheses could explain this observation. Behavioral toxicity in intermediate animals may result from aggregation in a subset of neurons, or Q35 and Q40 proteins may be in an intermediate biophysical state, both of which could result in neurotoxicity without overt foci formation.

\section{Dynamic biophysical properties of intermediate polyQ tracts in the VNC}

To determine whether there is a link between behavioral phenotypes and biochemical states in Q40 animals, we examined neurons associated with motility in which the most significant differences in polyQ length-dependent toxicity were observed. The highest concentration of neurons that regulate motility were found in the VNC. We reasoned that the visual assessment of polyQ state might not detect subtle biophysical changes in Q40 aggregation state or that Q40 could coexist in an aggregation or soluble state in individual neurons. To address this, we used FRAP analysis on multiple individual neurons distributed throughout the VNC of a single animal (Fig. $5 A-D$ ). Our results revealed that Q40::YFP recovery from photobleaching varies widely in the VNC. Q40 protein solubility either exists in a rapid recovery state in certain neurons (Fig. $5 A, D$ ), similar to that observed for soluble Q19, or is completely immobile in other neurons (Fig. 5C,D), similar to the Q86 aggregates, despite the absence of overt visual foci. Areas within Q40 VNC displaying rapid but partial recovery (Fig. $5 B, D$ ) can also be observed, suggesting that both soluble and immobile polyQ can coexist within individual neurons. Although areas of insoluble Q40 protein were observed along the VNC in the three independent transgenic Q40 lines tested, insoluble Q40 was not observed in neurons in head or tail ganglia, despite extensive FRAP testing. The sensitivity of FRAP analysis performed in living animals enabled a distinction to be made between mobile and immobile species in different sets of neurons that is not possible with standard biochemical methods. Consistent with the FRAP results of Q40 animals, a significant fraction of SDS-resistant aggregates was not detected by Western blot analysis of whole-animal extracts (supplemental Fig. 3, available at www.jneurosci.org as supplemental material). Q67 extracts displayed an aggregate fraction that was SDS resistant, characteristic of polyQ aggregates (Scherzinger et al., 1999; Satyal et al., 2000), whereas Q19 protein was soluble. Our results showed that FRAP analysis is much more sensitive for the detection of soluble and insoluble polyQ in individual neurons, which would not be possible with the biochemical approaches of whole-animal extracts (Fig. 5).

The molecular heterogeneity of intermediate polyQ protein solubility observed in Q40 animals led us to hypothesize that heterogeneity might also exist in the visual distribution pattern of Q40 proteins at higher magnification. We found subtle yet consistent changes in distribution, with areas of increased fluorescent intensity in oblong shapes with well defined, tapered ends (Fig. $5 F$ ). In contrast, at high magnification, the distribution of Q19 remained diffuse throughout, with roughly rounded cell bodies and processes, whereas Q86 protein was localized exclusively in sharply defined foci absent in Q40 animals (Fig. 5E, G).

To determine whether the intermediate-length Q40 displayed intermolecular interactions distinct from short (Q19) or long (Q86) polyQ, we next performed FRET analysis. In a single young adult Q40 animal, we tested individual neurons along the entire length of the VNC by FRAP to enable correlation of FRET results with Q40 solubility. Therefore, immediately after FRAP, the same region was tested for FRET. In regions of the VNC in which FRAP results indicated soluble Q40 protein, photobleaching of the YFP acceptor (Fig. 6C) had only a slight effect on donor intensity (Fig. $6 E$ ). We interpret these results to mean that any Q40-Q40 protein interactions occurring in the area of interest were either less stable or weak. Conversely, in regions where FRAP revealed the presence of insoluble $\mathrm{Q} 40$ protein in the $\mathrm{VNC}$ of the same animal (Fig. 6B), FRET was also observed (Fig. 6D,F). These results show that regions of Q40 expression in the VNC that were insoluble by FRAP also exhibited an intense FRET signal. To examine the extent of heterogeneity in Q40 intermolecular interactions, we analyzed the results of multiple FRET assays from the VNC of a Q40 animal. A scatter plot of the efficiency of interaction $\left(E_{\mathrm{i}}\right)$ revealed the presence of two populations of $E_{\mathrm{i}}$ that can coexist within the neurons of a single Q40 animal (Fig. 6G). In contrast, Q19 or Q86 animals displayed only a single type of intermolecular interaction (soluble or insoluble, respectively, in the VNC) (Fig. 6G). In addition, we observed a correlation between FRAP and FRET results; areas that were insoluble by FRAP were FRET positive, whereas proteins that were soluble by FRAP were always FRET negative. Together, the dynamic imaging techniques of FRET and FRAP provide an ability to obtain complementary data on the expression profile of Q40 in vivo that reveals a molecular heterogeneity of biophysical states of an intermediate-length polyQ protein in the neurons of a multicellular organism.

These results show that Q40 can exhibit polymorphic subcellular distribution, solubility, and intermolecular interactions in neurons of an individual animal, whereas expansions above the threshold have homogeneous distribution, solubility, and intermolecular interactions. The observed variation in biophysical properties of Q40 combined with the motility results that show behavioral phenotypes among individual Q40 animals ranging from wild type to severely impaired reveals that polyQ-mediated neurotoxicity in C. elegans can be observed in the absence of overt foci formation.

\section{Neuron-specific responses to polyQ proteins}

Our observation that the solubility of Q40 in C. elegans can vary among different areas of the nervous system suggests that there are modifiers acting on polyQ proteins independent of protein 

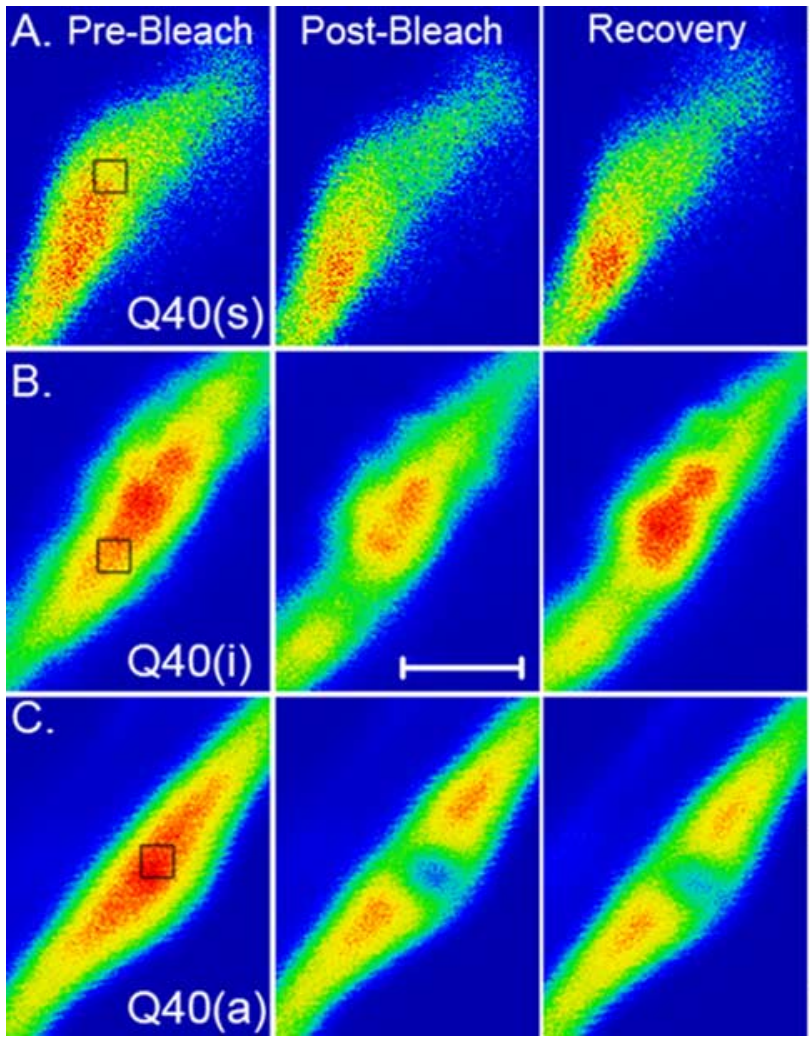
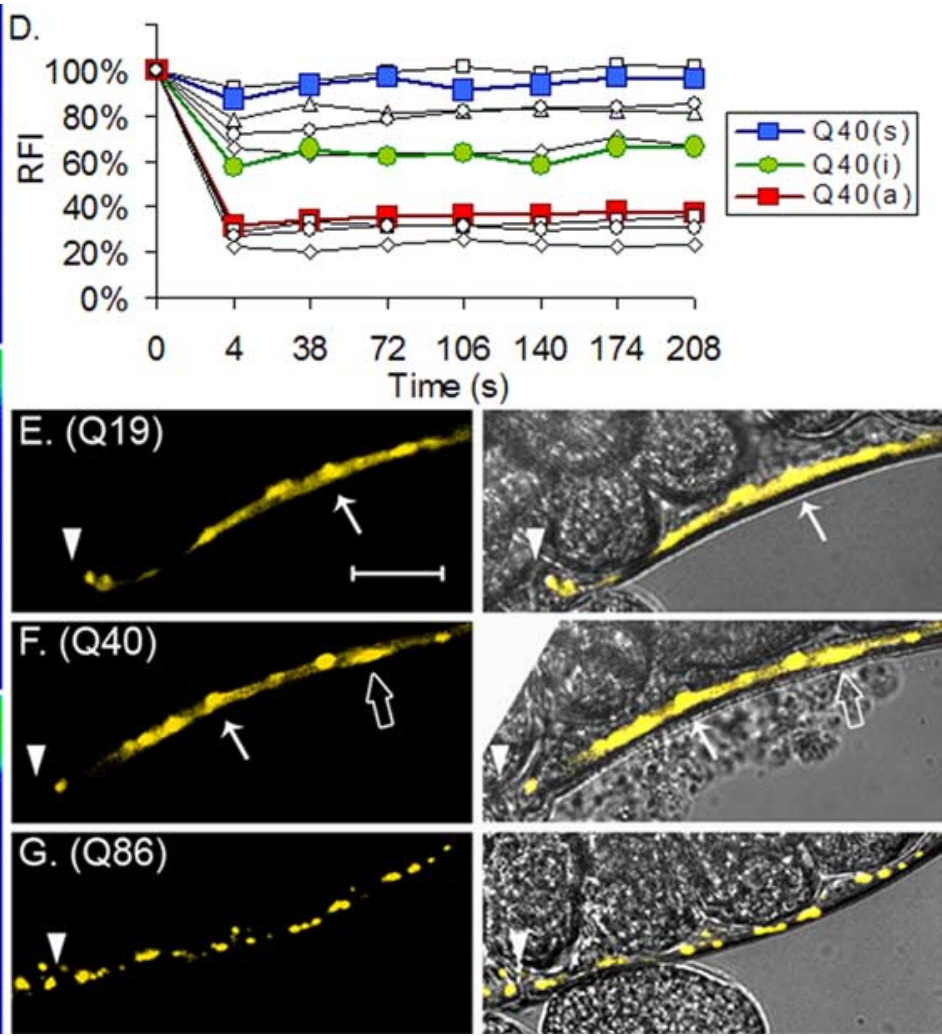

Figure 5. FRAP experiments reveal that Q40 solubility in the VNC varies widely ( $A-D)$. Data shown are representative of three independent Q40 lines tested. Quantification of data is from FRAP experiments in a single $Q 40$ animal $(\boldsymbol{D})$. Each line, including those with open symbols, is an individual experiment rather than an average of several cells, as shown Figure $3 D$. Q40 protein can recover

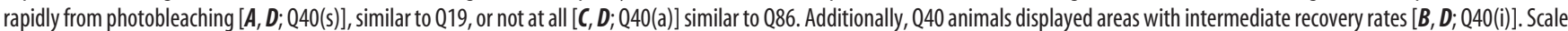
bar, $2 \mu \mathrm{m}$. Filled triangles indicate the vulva. Q19 distribution is diffuse, with rounded cell bodies $(\boldsymbol{E})$, whereas $Q 86$ protein is contained in well defined foci (G). Q40 is similar to $Q 19$ in appearance except in the VNC, where sharply tapered, intensely fluorescent areas can be detected $(\boldsymbol{F})$. Filled arrows indicate areas soluble by FRAP $(\boldsymbol{E}, \boldsymbol{F})$, whereas the open arrow indicates the area with decreased solubility $(\boldsymbol{F})$. Scale bar, $20 \mu \mathrm{m}$. RFI, Relative fluorescence intensity; (a), aggregated; (i), intermediate; (s), soluble.

context; however, this could also result from stochastic aggregation throughout the nervous system. To distinguish between neuron-specific or stochastic solubility, we extended our FRAP analysis to include specific neurons in multiple animals. We reasoned that if the solubility of Q40 protein is stochastic, protein solubility in a specific neuron will vary between animals; however, if the solubility of polyQ is neuron specific, FRAP results should be consistent among different animals.

To examine the pattern of neuron-specific solubility between animals, we generated a C. elegans line with the $\mathrm{P}_{\mathrm{F} 25 \mathrm{~B} 3.3} \mathrm{Q} 40:: \mathrm{YFP}$ array integrated for more consistent expression of the transgene. In these integrated lines we identified individual neurons, such as the BDU interneuron, the ALM mechanosensory neuron, the HSN, and the CAN, and performed FRAP experiments (Fig. $7 A, B)$. In these specific neurons, cell bodies, and processes, Q40 was consistently soluble, whereas in the $\mathrm{VNC}$ and $\mathrm{DNC}$, both soluble and immobile states of Q40 were observed (Fig. 7C,D). These data provide several insights. First, from these data we conclude that the solubility of Q40 in the nervous system of $C$. elegans is cell specific and not stochastic, which suggests that polyQ solubility is modulated by some property of the neuron in which it is expressed.

Second, these data also reveal that intermediate-length polyQ solubility is not a function solely of its subcellular localization to the cell body versus neuronal processes. Soluble Q40 was detected in both cell bodies and processes of the specific neurons described previously. Immobile as well as soluble Q40 was identified in the DNC. Because the DNC is predominantly formed from processes of motor neurons, with only a single cell body near the isthmus of the pharynx (White et al., 1986), FRAP analysis of the DNC revealed that immobile Q40 protein can be also found in neuronal processes. Both states of Q40 solubility were detected throughout the $\mathrm{VNC}$, which is densely packed with the cell bodies of 57 motor neurons in addition to a high concentration of neuronal processes.

Last, data presented on neuron-specific solubility of threshold-length polyQ protein revealed that in the DNC or VNC, Q40 forms an immobile species more frequently than elsewhere in the animal. In addition to the specific neurons described previously, FRAP was performed on neurons in both the head and tail (data not shown), but none revealed decreases in solubility comparable with that seen in the DNC or VNC. Together, these data suggest that some characteristic specific to the neurons bundled into the nerve cords of $C$. elegans, such as neuronal function, connectivity, activity levels, or expression levels of polyQ proteins, acts as a specific modifier of polyQ proteins at the pathogenic threshold.

Aging, which is a major contributor to the onset of polyQ aggregation in both humans and model systems, may modify polyQ solubility in C. elegans neurons. Previous work from our laboratory has shown that polyQ aggregation progresses in an age-dependent manner in muscle cells (Morley et al., 2002). To establish whether the polyQ solubility changes in C. elegans neurons during aging, we analyzed solubility in specific neurons of young adult (4 d old) and aged animals. Unexpectedly, Q40 in these neurons remained soluble in animals that were up to $10 \mathrm{~d}$ 
old (Fig. 7C), suggesting that Q40 solubility is not affected by aging in these neurons. In the nerve cords, both soluble and immobile species of Q40 were detected as early as $3 \mathrm{~d}$, and heterogeneity persisted as animals aged (Fig. 7D). These results highlight the polymorphic biochemical properties of Q40 and show that specific neurons are able to maintain Q40 solubility as they age. These properties of Q40 are in contrast to the complete aggregation of Q67 or Q86 proteins that we observed in the C. elegans nervous system (Fig. 1) and suggest that for intermediate Q lengths, age is not the only modifier of polyQ protein solubility.

\section{Discussion}

The animal model presented here for panneuronal polyQ expression in C. elegans allows the simultaneous examination of polyQ pathogenesis at the level of individual neurons as well as its effect on the behavior of a live animal. Our characterization of this new $C$. elegans model reveals that pan-neuronal expression of polyQ proteins recapitulates critical features of neurodegenerative disease, including polyQ length-dependent neuronal aggregation and toxicity. Additionally, we have observed for the first time that C. elegans neurons exhibit a pathogenic threshold of 35-40 glutamine repeats. We have taken advantage of $C$. elegans by applying biophysical techniques that are commonly associated with in vitro experiments or cultured cells to show by single-cell analysis that an intact multicellular model reveals subtleties not detected by standard biochemistry or immunohistochemistry approaches. Specifically, we show that intermediate-length polyQ proteins expressed in live neurons display cell typespecific differences in solubility and intermolecular interactions, accounting for the behavioral phenotypes observed in the absence of discrete foci.

Previous studies examining patient samples, mouse brain, or the Drosophila eye have relied principally on the use of fixed tissue and extremely large polyQ expansions to determine the localization of polyQ proteins into inclusions detectable by immunohistochemistry or fluorescent microscopy (Faber et al., 1999; Satyal et al., 2000; Parker et al., 2001; Morley et al., 2002; Zoghbi and Botas, 2002; Shulman et al., 2003). The presence of inclusions is often confirmed by the existence of protein species that are SDS resistant. Together, these approaches have resulted in a large body of literature that clearly establishes that at large expansions $(>80)$, polyQ proteins alone or in the context of disease proteins form inclusions in subsets of neuronal tissue, although the protein is expressed throughout the nervous system. It is not possi-
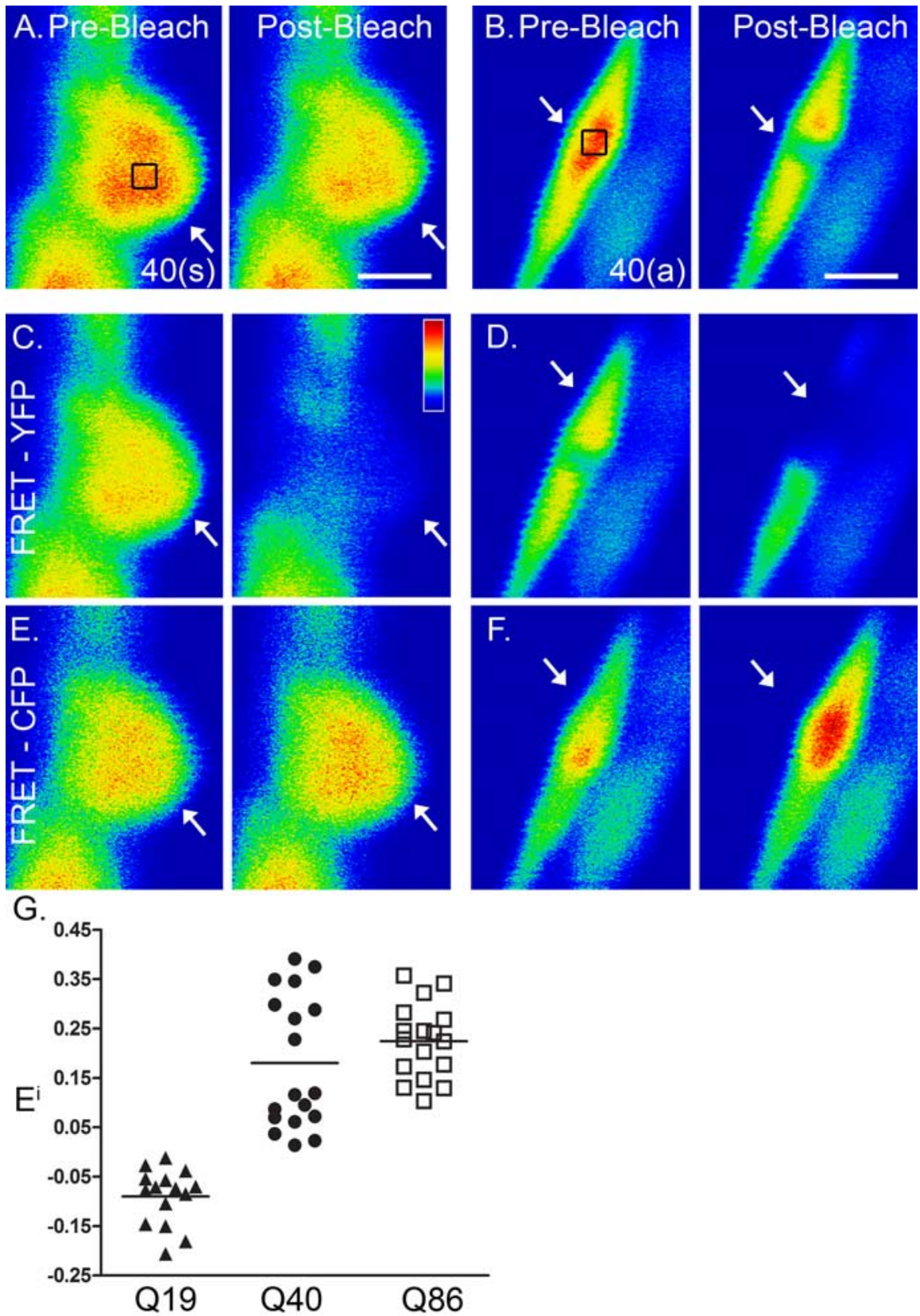

Figure 6. FRET analysis of Q40 proteins in C. elegans neurons reveals two distinct populations of intermolecular interactions in young adult animals. $\boldsymbol{A}, \boldsymbol{B}$, FRAP was performed to determine protein solubility before FRET analysis. Photobleaching was performed inside the boxes. Recovery from FRAP $(\boldsymbol{A})$ was rapid, indicating soluble protein and labeled Q40(s). A second area in the same animal [Q40(a)] did not recover from photobleaching $(\boldsymbol{B})$, indicating insoluble protein, consistent with aggregation. FRET was performed on the areas of interest, indicated by arrows. $C, D$, YFP channel; $E, F$, CFP channel. Photobleaching of YFP $(\boldsymbol{C})$ has little effect on CFP intensity; therefore, no strong FRET was occurring (E). In contrast, YFP photobleaching (D) of insoluble Q40 proteins causes an increase in CFP intensity $(\boldsymbol{F})$, indicating that intermolecular interactions between $Q 40$ proteins are sufficient to generate FRET. Scale bars, $2 \mu \mathrm{m}$. G, Simple scatter plot of $E_{\mathrm{i}}$ from FRET experiments shows two populations of FRET-positive areas in a single $Q 40$ animal. Average \pm SD for Q19: $E_{\mathrm{i}},-0.090( \pm 0.05), n=15 ; \mathrm{Q} 40: E_{\mathrm{i}}, 0.180( \pm 0.13), n=18 ; \mathrm{Q} 86 \mathrm{E} E_{\mathrm{i}}, 0.224$ $( \pm 0.07), n=17$. (a), Aggregated; (s) soluble.

ble, however, to obtain biophysical data on protein solubility and interaction at the molecular level with fixed tissue. Furthermore, it is not possible to examine characteristics of polyQ proteins in a specific neuron either over time or between animals, as is now possible in our C. elegans pan-neuronal model.

We have shown here that in specific C. elegans neurons, Q40 protein can form immobile, self-associating aggregates not detectable by traditional biochemistry or visualization of discrete 

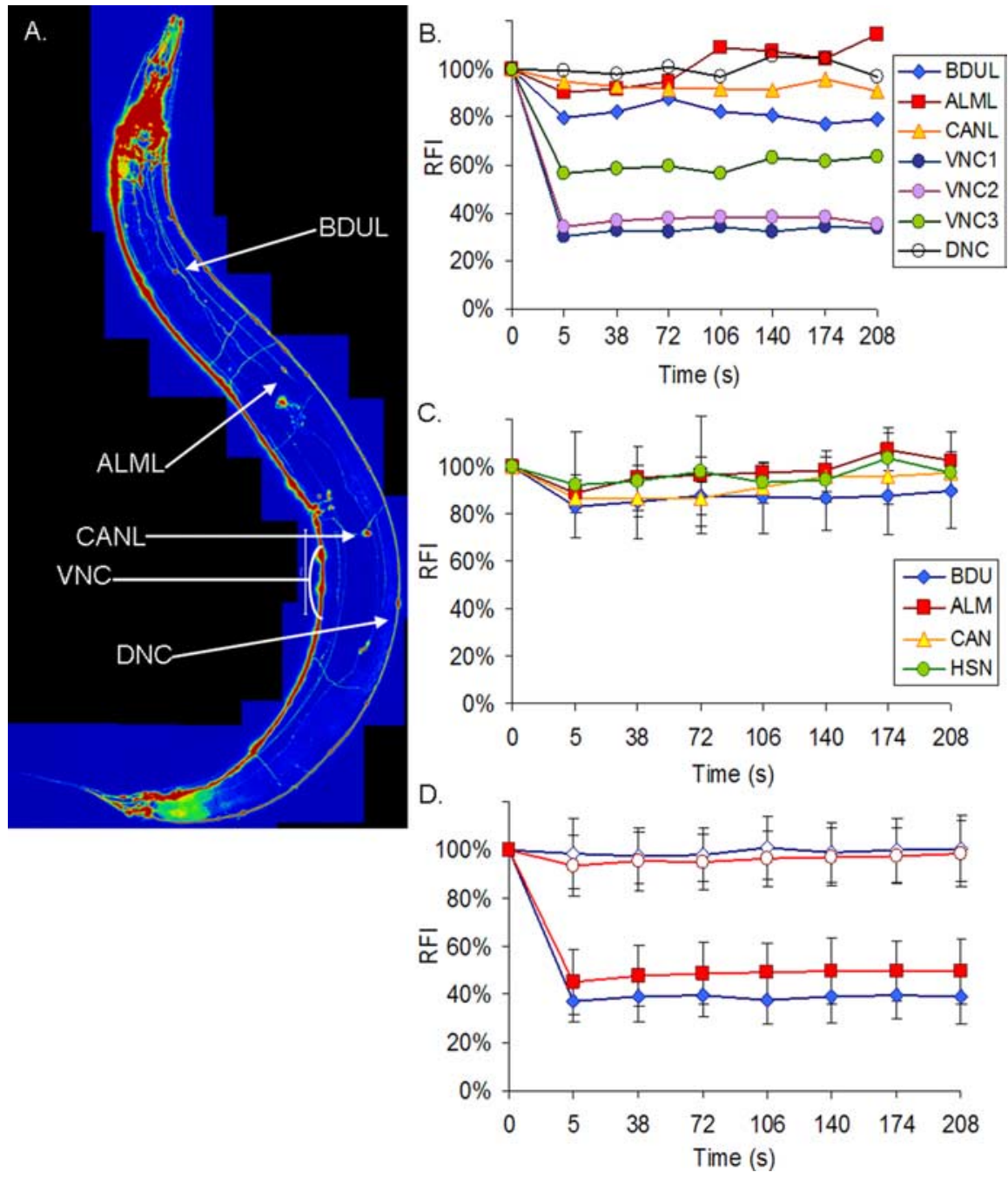

Figure 7. $A$, Specific neurons are identified in the flattened z-stack of a representative $Q 40$ animal ( $8 \mathrm{~d}$ old); $\boldsymbol{B}$, FRAP results are shown for each neuron or area identified in $A$. C, FRAP data shown are the average for each specific neuron, with SD, analyzed in animals from 4 to $10 \mathrm{~d}$ of age. In these neurons, $Q 40$ maintains a soluble state even in aged animals. $D$, In the DNC and VNC, solubility is polymorphic: soluble and immobile states can be observed in young adult animals or those aged to $8 \mathrm{~d}$. Data shown are the average, with SD of data grouped by recovery of $>50 \%$ for soluble and $<50 \%$ for immobile.

foci. Additionally, the Q40 protein in our model was clearly associated with a range of behavioral defects. This suggests that phenotypic pathology observed in the absence of inclusions or SDS-insoluble polyQ protein does not rule out the presence of other misfolded states of polyQ. Thus, our use of FRAP and FRET methods to directly assess the polyQ aggregation state contributes methodological approaches that increase significantly the resolution of aggregate states in individual neurons of a live, multicellular animal.

Our use of FRAP analyses of Q40 proteins also reveals the presence of molecular heterogeneity in the solubility of a threshold-length polyQ in living neurons. Together with a second imaging technique, FRET, these biophysical methods reveal how individual neurons of a live animal can be studied directly. In our pan-neuronal C. elegans model, Q86 exhibits an intense FRET signal, whereas Q19 does not, and Q40 displays heterogeneity of intermolecular interactions. These data provide the first confirmation of FRET between polyQ proteins in the neurons of a live multicellular organism. Although biophysical differences between proteins with a wide range of polyQ lengths have been well documented in vitro and in cell culture (Davies et al., 1997;
Holmberg et al., 1998; Kim et al., 2002), these studies represent an analysis of the biophysical properties of polyQ proteins in a live animal.

Generation of a pan-neuronal model in C. elegans has made it possible to compare tissue-specific responses to polyQ proteins. As reported previously, when polyQ proteins are expressed in muscle cells, both aggregation and toxicity are length dependent, with a pathogenic threshold of 35-40 repeats in young adult animals (Morley et al., 2002). It is reassuring, therefore, that polyQ pathogenesis in neurons occurs at the same threshold as seen in muscle cells. Together, these results reveal that the threshold for aggregation and toxicity in C. elegans is not a unique feature of tissue type, but rather is an intrinsic feature of polyQ proteins. The similarities in polyQ pathogenesis and threshold length between tissues of $\mathrm{C}$. elegans suggest that the gain of function associated with simple polyQ expansions is dependent on a fundamental, conserved mechanism, thus lending strong support for the use of our muscle cell models in identifying modifiers of polyQ pathogenesis.

An important difference between the neuronal model presented here and the body-wall muscle cell C. elegans model described previously can be observed at the threshold of polyQ aggregation. Although both models display the heterogeneous solubility of Q40 protein, aggregation in muscle cells did not occur in a cell typespecific manner, suggesting that aggregation in muscle cells is largely a stochastic event. In contrast, Q40 solubility in neurons was cell specific, and lateral neurons remained soluble even in aged animals.

Our C. elegans model provides a unique tool for investigating the basis of neuron-specific toxicity associated with the expression of polyQ proteins. Behavioral and molecular characterization of polyQ expansions in a pan-neuronal system are the first steps in establishing a model in which neuron-specific, novel modifiers of polyQ-mediated pathogenesis can be identified. Additionally, establishment of this system with polyQ protein alone, without the adjacent sequences of huntingtin or ataxin-1 or -3 , provides the baseline for future studies to examine one of the major modifiers of polyQ pathogenesis: protein context. The model presented here opens the way for comparative studies on how polyQ placed in the context of different disease genes, such as huntingtin, modifies neuron-specific responses to simple polyQ proteins. Together, these experiments provide the opportunity to elucidate cell-specific neurotoxicity and aggregation as seen in human neurodegenerative disease.

\section{References}

Albertson DG, Thomson JN (1976) The pharynx of Caenorhabditis elegans. Philos Trans R Soc Lond B Biol Sci 275:299-325.

Altun-Gultekin Z, Andachi Y, Tsalik EL, Pilgrim D, Kohara Y, Hobert O 
(2001) A regulatory cascade of three homeobox genes, ceh-10, ttx-3 and ceh-23, controls cell fate specification of a defined interneuron class in $C$. elegans. Development 128:1951-1969.

Avery L (1993) Motor neuron M3 controls pharyngeal muscle relaxation timing in Caenorhabditis elegans. J Exp Biol 175:283-297.

Avery L, Horvitz HR (1989) Pharyngeal pumping continues after laser killing of the pharyngeal nervous system of C. elegans. Neuron 3:473-485.

Bargmann CI, Kaplan JM (1998) Signal transduction in the Caenorhabditis elegans nervous system. Annu Rev Neurosci 21:279-308.

Berney C, Danuser G (2003) FRET or no FRET: a quantitative comparison. Biophys J 84:3992-4010.

Brenner S (1974) The genetics of Caenorhabditis elegans. Genetics 77:71-94.

Brownlee DJ, Fairweather I (1999) Exploring the neurotransmitter labyrinth in nematodes. Trends Neurosci 22:16-24.

Chai Y, Shao J, Miller VM, Williams A, Paulson HL (2002) Live-cell imaging reveals divergent intracellular dynamics of polyglutamine disease proteins and supports a sequestration model of pathogenesis. Proc Natl Acad Sci USA 99:9310-9315.

Dal Santo P, Logan MA, Chisholm AD, Jorgensen EM (1999) The inositol trisphosphate receptor regulates a 50-second behavioral rhythm in C. elegans. Cell 98:757-767.

Davies SW, Turmaine M, Cozens BA, DiFiglia M, Sharp AH, Ross CA, Scherzinger E, Wanker EE, Mangiarini L, Bates GP (1997) Formation of neuronal intranuclear inclusions underlies the neurological dysfunction in mice transgenic for the HD mutation. Cell 90:537-548.

DiFiglia M, Sapp E, Chase KO, Davies SW, Bates GP, Vonsattel JP, Aronin N (1997) Aggregation of huntingtin in neuronal intranuclear inclusions and dystrophic neurites in brain. Science 277:1990-1993.

Ebinu JO, Bottorff DA, Chan EY, Stang SL, Dunn RJ, Stone JC (1998) RasGRP, a Ras guanyl nucleotide-releasing protein with calcium- and diacylglycerol-binding motifs. Science 280:1082-1086.

Faber PW, Alter JR, MacDonald ME, Hart AC (1999) Polyglutaminemediated dysfunction and apoptotic death of a Caenorhabditis elegans sensory neuron. Proc Natl Acad Sci USA 96:179-184.

Gusella JF, MacDonald ME (2000) Molecular genetics: unmasking polyglutamine triggers in neurodegenerative disease. Nat Rev Neurosci 1:109-115.

Holmberg M, Duyckaerts C, Durr A, Cancel G, Gourfinkel-An I, Damier P, Faucheux B, Trottier Y, Hirsch EC, Agid Y, Brice A (1998) Spinocerebellar ataxia type 7 (SCA7): a neurodegenerative disorder with neuronal intranuclear inclusions. Hum Mol Genet 7:913-918.

Kawasaki H, Springett GM, Toki S, Canales JJ, Harlan P, Blumenstiel JP, Chen EJ, Bany IA, Mochizuki N, Ashbacher A, Matsuda M, Housman DE, Graybiel AM (1998) A Rap guanine nucleotide exchange factor enriched highly in the basal ganglia. Proc Natl Acad Sci USA 95:13278-13283.

Kim S, Nollen EA, Kitagawa K, Bindokas VP, Morimoto RI (2002) Polyglutamine protein aggregates are dynamic. Nat Cell Biol 4:826-831.

Lippincott-Schwartz J, Patterson GH (2003) Development and use of fluorescent protein markers in living cells. Science 300:87-91.

Margolis RL, Ross CA (2001) Expansion explosion: new clues to the pathogenesis of repeat expansion neurodegenerative diseases. Trends Mol Med $7: 479-482$.

McIntire SL, Jorgensen E, Kaplan J, Horvitz HR (1993) The GABAergic nervous system of Caenorhabditis elegans. Nature 364:337-341.

Miyawaki A (2003) Visualization of the spatial and temporal dynamics of intracellular signaling. Dev Cell 4:295-305.

Miyawaki A, Tsien RY (2000) Monitoring protein conformations and interactions by fluorescence resonance energy transfer between mutants of green fluorescent protein. Methods Enzymol 327:472-500.

Morley JF, Brignull HR, Weyers JJ, Morimoto RI (2002) The threshold for polyglutamine-expansion protein aggregation and cellular toxicity is dynamic and influenced by aging in Caenorhabditis elegans. Proc Natl Acad Sci USA 99:10417-10422.
Orr HT (2001) Beyond the Qs in the polyglutamine diseases. Genes Dev 15:925-932.

Parker JA, Connolly JB, Wellington C, Hayden M, Dausset J, Neri C (2001) Expanded polyglutamines in Caenorhabditis elegans cause axonal abnormalities and severe dysfunction of PLM mechanosensory neurons without cell death. Proc Natl Acad Sci USA 98:13318-13323.

Perutz MF (1999) Glutamine repeats and neurodegenerative diseases: molecular aspects. Trends Biochem Sci 24:58-63.

Phair RD, Misteli T (2000) High mobility of proteins in the mammalian cell nucleus. Nature 404:604-609.

Poirier MA, Jiang H, Ross CA (2005) A structure-based analysis of huntingtin mutant polyglutamine aggregation and toxicity: evidence for a compact beta-sheet structure. Hum Mol Genet 14:765-774.

Rand JB, Nonet ML (1997) Chapter 22. Synatptic transmission. In: C. elegans II (Riddle DL, Blumenthal T, Meyer BJ, Priess JR, eds). Plainview, NY: Cold Spring Harbor Laboratory.

Rankin CH (2002) From gene to identified neuron to behaviour in Caenorhabditis elegans. Nat Rev Genet 3:622-630.

Ross CA (1995) When more is less: pathogenesis of glutamine repeat neurodegenerative diseases. Neuron 15:493-496.

Ross CA, Poirier MA (2004) Protein aggregation and neurodegenerative disease. Nat Med [Suppl] 10:10-17.

Ross CA, Poirier MA, Wanker EE, Amzel M (2003) Polyglutamine fibrillogenesis: the pathway unfolds. Proc Natl Acad Sci USA 100:1-3.

Satyal SH, Schmidt E, Kitagawa K, Sondheimer N, Lindquist S, Kramer JM, Morimoto RI (2000) Polyglutamine aggregates alter protein folding homeostasis in Caenorhabditis elegans. Proc Natl Acad Sci USA 97:5750-5755.

Scherzinger E, Sittler A, Schweiger K, Heiser V, Lurz R, Hasenbank R, Bates GP, Lehrach H, Wanker EE (1999) Self-assembly of polyglutaminecontaining huntingtin fragments into amyloid-like fibrils: implications for Huntington's disease pathology. Proc Natl Acad Sci USA 96:4604-4609.

Sherman MY, Muchowski PJ (2003) Making yeast tremble: yeast models as tools to study neurodegenerative disorders. Neuromolecular Med 4:133-146.

Shulman JM, Shulman LM, Weiner WJ, Feany MB (2003) From fruit fly to bedside: translating lessons from Drosophila models of neurodegenerative disease. Curr Opin Neurol 16:443-449.

Sze JY, Victor M, Loer C, Shi Y, Ruvkun G (2000) Food and metabolic signaling defects in a Caenorhabditis elegans serotonin-synthesis mutant. Nature 403:560-564.

Tonkiss J, Calderwood SK (2005) Regulation of heat shock gene transcription in neuronal cells. Int J Hyperthermia 21:433-444.

Tsien RY (1998) The green fluorescent protein. Annu Rev Biochem 67:509-544.

White J, Stelzer E (1999) Photobleaching GFP reveals protein dynamics inside live cells. Trends Cell Biol 9:61-65.

White JG, Southgate E, Thomson JN, Brenner S (1976) The structure of the ventral nerve cord of Caenorhabditis elegans. Philos Trans R Soc Lond B Biol Sci 275:327-348.

White JG, Southgate E, Thomson JN, Brenner S (1986) The structure of the nervous system of the nematode Caenorhabditis elegans. Philos Trans R Soc Lond B Biol Sci 314:1-340.

Wouters FS, Bastiaens PI, Wirtz KW, Jovin TM (1998) FRET microscopy demonstrates molecular association of non-specific lipid transfer protein (nsL-TP) with fatty acid oxidation enzymes in peroxisomes. EMBO J 17:7179-7189.

Zoghbi HY, Botas J (2002) Mouse and fly models of neurodegeneration. Trends Genet 18:463-471.

Zoghbi HY, Orr HT (2000) Glutamine repeats and neurodegeneration. Annu Rev Neurosci 23:217-247. 